\title{
Development of Indicator Based on Oil Analysis for Estimating Risk Level of Power Transformers
}

\author{
Gints Poiss \\ Augstsprieguma tīkls JSC \\ Riga, Latvia \\ gints.poiss@ast.lv
}

\author{
Sandra Vitolina; Janis Marks \\ Department of Electrical Machines and Devices \\ Riga Technical University \\ Riga, Latvia \\ sandra.vitolina@rtu.lv; janis.marks@rtu.lv
}

\begin{abstract}
Risk assessment for power transformers has long been an effective tool to analyze transformer conditions in order to prevent damage on transformers, extend transformer's life time and reduce maintenance costs. Various parameters can be evaluated, and decision can be made manually or with the help of mathematical model. A new mathematical risk-assessment model for power transformers is being developed for power system in Latvia, based on specific maintenance features and 4 indicators: dissolved gas analysis; oil analysis, electrical measurements and operation history.
\end{abstract}

This paper specifies oil analysis as one of the indicators of regular risk assessment of power transformers. Development of this indicator is presented based on traditional binary evaluation algorithm combined with fuzzy logic, and as a case study results of oil parameters from different transformers are analyzed and discussed.

Keywords—oil filled transformers; fuzzy logic; risk analysis.

\section{INTRODUCTION}

Oil filled power transformers remain the most commonly used for a variety of industrial, commercial and power utility applications. Transformer oil serves as liquid insulation, dissipates heat of the transformer and radiators of transformer accelerates the cooling rate. Furthermore, one of its main functions is information accumulation since oil is an organic substance which quality gradually reduces and it also contains ageing products of solid insulation.

Globally, every individual power system chooses their own way to reduce the risk of power transformer failure and to increase its power system reliability. A common global practice is to develop a risk matrix model in the last stage of transformer evaluation, where the probability of failure and the severity of potential consequences are assessed in order to visually depict the significance of potential fault [1], [2], [3]. Each power system has to develop its own individual strategy for power transformer risk assessment since diagnostic tools, periodicity of tests and technical standards applied may be different, as well as specific features such as ageing of installed units, loading, oil volumes etc.

Indicators for the risk matrix for power system in Latvia are proposed in [4] (see Table I). Indicators have been selected based on the available diagnostic tools, and also to cover different important sections of a power transformer.

The objective of the paper is to develop a method for determining the numerical value of the indicator based on oil analysis.

TABLE I. CONDITION INDICATORS AND PARAMETERS

\begin{tabular}{|c|c|c|c|}
\hline \multirow{2}{*}{$\begin{array}{c}\text { Operation } \\
\text { and } \\
\text { maintenance }\end{array}$} & \multicolumn{2}{|c|}{ Transformer oil } & \multirow{2}{*}{$\begin{array}{c}\text { Electrical } \\
\text { measurements }\end{array}$} \\
\hline & Oil analysis & $D G A$ & \\
\hline Age & Flash point & $\mathrm{H}_{2}, \mathrm{CH}_{4}$ & Insulation resistance \\
\hline Loading & Dissipation factor & $\mathrm{C}_{2} \mathrm{H}_{4}$ & Tan $\delta$ \\
\hline $\begin{array}{c}\text { Tripping per } \\
\text { year }\end{array}$ & Acidity & $\mathrm{C}_{2} \mathrm{H}_{6}$ & No-load loss \\
\hline $\begin{array}{c}\text { Importance } \\
\text { in the system }\end{array}$ & Moisture content & $\mathrm{C}_{2} \mathrm{H}_{2}$ & Winding resistance \\
\hline $\begin{array}{l}\text { Maintenace } \\
\text { history }\end{array}$ & & $\mathrm{CO}, \mathrm{CO}_{2}$ & $\begin{array}{l}\text { FRA and Short-circuit } \\
\text { impedance }\end{array}$ \\
\hline
\end{tabular}

\section{ASSESSMENT OF TRANSFORMER OIL PARAMETERS}

Generally mineral transformer oil is used in power transformers in power system of Latvia. According to Electrotechnical Commission (LEK) standard [5] oil sampling periodicity for power transformers of installed in substations is 4 years. Assessment limits for oil parameters are defined in this standard as well. Traditional LEK standard-based assessment methodology of the measurement results prescribe comparison of data obtained in laboratory with the given assessments limits, and conclusions are obtained for each oil parameter separately rather than as a single entity.

Transformer oil parameters regularly measured are dielectric strength, moisture content, acidity, dielectric dissipation factor, interfacial tension, viscosity, flash point, and sludge content. In order to form the oil analysis indicator, 4 independent parameters were selected from this list.

Flash point is the lowest temperature at which oil in certain conditions releases such amount of vapour that, together with air, creates a flammable mixture leading to fire hazard. Therefore, this parameter, as well as its fluctuations over $5^{\circ} \mathrm{C}$ has been proposed as one of parameters indicating high risk. As the second parameter, dissipation factor tan $\delta$ has been 
proposed since it is highly sensitive to oil aging, moisture, as well as changes in contamination levels.

Dissipation factor tan $\delta$ along with acidity and moisture content have been proposed as criteria for medium risk evaluation. In order to reach a unified conclusion regarding the correlation between these independent oil parameters, the use of fuzzy logic is suggested.

It should be noted that limits for oil parameters shown in Table 2 are based on typical values observed for transformers installed in transmission network in Latvia and differs slightly from limits given in [5].

TABLE II. PROPOSED LIMITS FOR OIL PARAMETERS

\begin{tabular}{|c|c|c|c|c|}
\hline $\begin{array}{l}\text { Upper } \\
\text { limit }\end{array}$ & $\begin{array}{c}\text { Flash point, } \\
{ }^{\circ} \mathrm{C}\end{array}$ & $\begin{array}{l}\text { Acidity, } \\
\text { mgKOH/g }\end{array}$ & $\begin{array}{c}\text { Moisture } \\
\text { content, } \\
\text { ppm }\end{array}$ & $\underset{\%}{\operatorname{Tan} \delta}$ \\
\hline Level 1 & \multirow{3}{*}{$\begin{array}{l}125 \text { or } \geq \Delta 5 \text { in } \\
2 \text { subseqent } \\
\text { measurements }\end{array}$} & $<0.05$ & $<5$ & $<1$ \\
\hline Level 2 & & $\leq 0.1$ & $\leq 10$ & $\leq 4$ \\
\hline Level 3 & & $>0.1$ & $>15$ & $>4$ \\
\hline
\end{tabular}

\section{APPLICATION OF FUZZY LOGIC}

\section{A. An Overview of Fuzzy Logic}

Fuzzy logic in its essence differs from regular - binary logic where statements can only be either true or false. In fuzzy logic these statements can have a third state - partial affiliation where it can range from 0 to 1 . Fig. 1 shows the difference of these two logics. Fig. 1a displays the process of binary logic. Value of $y$ is either 1 or 0 depending on the value of $x$. Fig. $1 b$ displays the same process with fuzzy logic. There are still $\mathrm{x}$ values that generate clear y value of 1 or 0 . However, there is now a period in between these regions where the value of $y$ can be a decimal number. This must not be viewed as a probability but rather as an affiliation to the function.
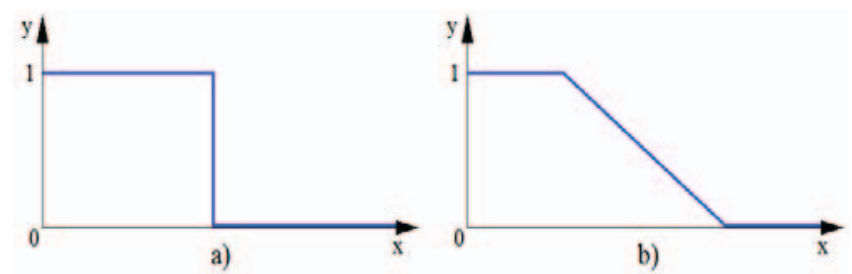

Fig. 1. Function graphs with binary and fuzzy logics.

In fuzzy logic, these input functions are called membership functions and the process of obtaining their values is called fuzzification [6]. Furthermore, the shape of these membership functions can be varying. The simplest ones are tringle and trapeze-shaped. These types consist only of straight line. However, more complex shapes can be used with bent lines within the function graph.

Next step of problem solving with fuzzy logic is the creation of rules. These rules are required to determine which output function is active based on the given input. They consist of logical operations AND, OR and IF.
The output functions are similar to the input functions as mentioned before. Applying rules to given input functions shows the path to the corresponding output function. Multiple output functions can be active since input functions can overlap for a single input value and that gives numerous variations for a possible result. The total output function is obtained by adding all single output function results together. Afterwards, defuzzification is required to obtain a single value as a result. This is achieved by calculating the gravity center of the total output function [6]. An example of this procedure is shown in Fig. 2 with a thick black line that goes through both functions $\mathrm{y}_{1}$ and $\mathrm{y}_{2}$.

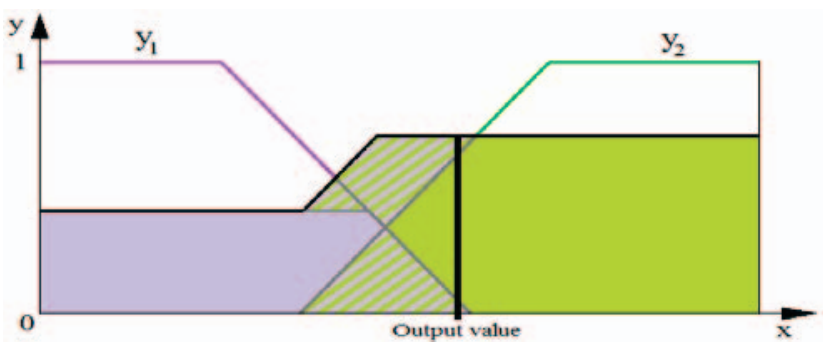

Fig. 2. Output functions and value.

\section{B. Transformer Diagnostic Using Fuzzy Logic}

There is large amount of researches being done with power transformer diagnostics using fuzzy logic system [7, 8, 9, 10]. Generally, the input variables, chosen input membership function types and output membership functions differ. The diagnostics of power transformers can be relatively complex since there are multiple parameters that must be taken in consideration [7, 8]. Dissolved gas analysis (DGA) is the most frequently used parameter. Here the input variables are the content of individual chemicals dissolved in the oil of transformer such as carbon monoxide $(\mathrm{CO})$, carbon dioxide $\left(\mathrm{CO}_{2}\right)$, hydrogen $\left(\mathrm{H}_{2}\right)$, methane $\left(\mathrm{CH}_{4}\right)$, ethylene $\left(\mathrm{C}_{2} \mathrm{H}_{4}\right)$, ethane $\left(\mathrm{C}_{2} \mathrm{H}_{6}\right)$ and acetylene $\left(\mathrm{C}_{2} \mathrm{H}_{2}\right)[9,10]$. Each of them have recommended values. Input membership functions can be made from these criteria. Fig. 3 shows the created functions for ethylene $\left(\mathrm{C}_{2} \mathrm{H}_{4}\right)$ in a study carried out by researchers [9].

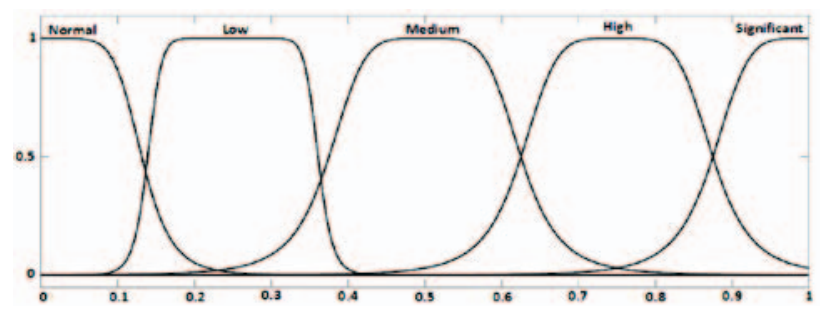

Fig. 3. Input variable $\left(\mathrm{C}_{2} \mathrm{H}_{4}\right)$ membership functions [9].

This input variable consists of 5 different membership functions. Furthermore, they overlap. Therefore, there will be multiple results for some values of ethylene.

Similar process is carried out for other chemical components. Afterwards, rules are applied and output membership functions are used to generate a result (risk). 
The input variables can range beyond dissolved gas analysis and can consist for example of frequency response analysis (SFRA) [7].

\section{Development of The OIL IndicAtor}

Oil parameters described previously in chapter 2 are used to analyze the condition of a power transformer. They are flash point, dissipation factor $\tan \delta$, acidity, moisture content and difference in values of flash point in two subsequent measurements (flash point $\Delta$ ). The proposed method uses all 5 as input parameters. The output indicator ranges from 1 (best possible output) to 5 (worst possible output).

First step of the proposed algorithm (see Fig. 4.) is the evaluation whether all parameters are at low risk. If this condition is met, output of $\mathrm{K}=1$ is given. Otherwise, the next evaluation follows whether one of three parameters exceeds limits given in Table II. If this is true, output of $\mathrm{K}=5$ is given. These segments of algorithm are not part of fuzzy logic and are exclusion cases. Afterwards, fuzzy logic calculation block becomes active. It calculates the accurate output based on the values of input parameters and created set of rules. The possible outputs from this section of the algorithm are from 2 to 4 .

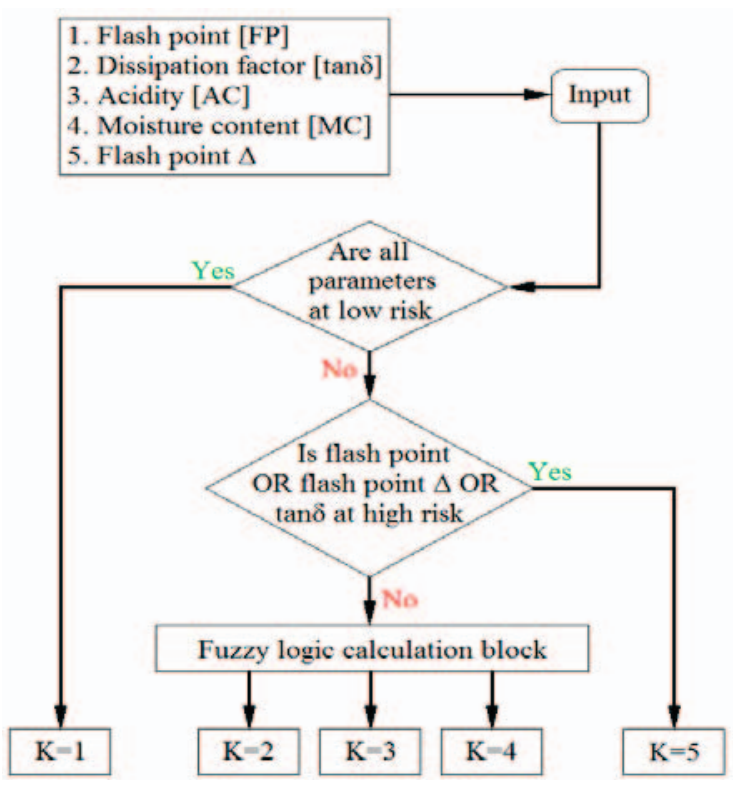

Fig. 4. Flowchart for oil analysis indicator.

Limits given in Table II are used for definition if variable is low, medium or high in fuzzy logic calculation block. Fig. 5. shows the created membership functions for all the input variables. Green line indicates low risk [L], blue line - medium risk $[\mathrm{M}]$ and red line corresponds to high risk $[\mathrm{H}]$.

Each input variable has its own impact on the power transformer. Therefore, the set of rules of obtaining output must be created correspondingly. Therefore, there are in total 27 rules created (see Table III). Furthermore, all rules consist of the logical operator AND.
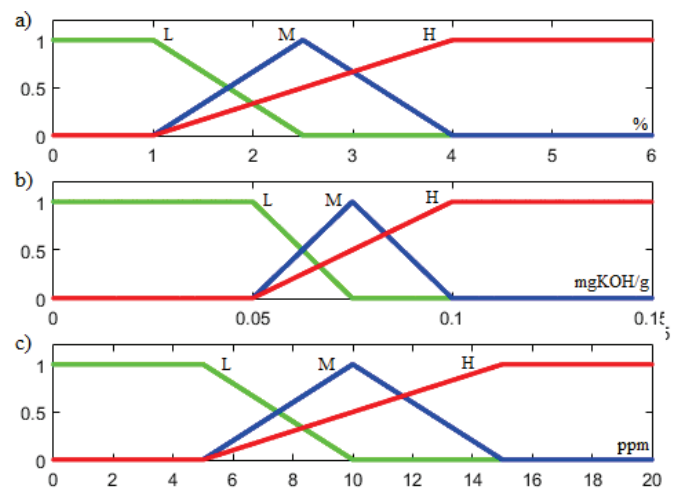

Fig. 5. Membership functions for input variables. a) dissipation factor $[\tan \delta]$; b) acidity $[\mathrm{AC}]$; c) moisture content $[\mathrm{MC}]$.

TABLE III. CREATED SET OF RULES

\begin{tabular}{|c|c|c|c|c|c|c|c|c|c|}
\hline \multirow{2}{*}{$\#$} & \multicolumn{3}{|c|}{ Input Variables } & \multirow{2}{*}{ Output } & \multirow{2}{*}{ \# } & \multicolumn{3}{|c|}{ Input Variables } & \multirow{2}{*}{ Output } \\
\hline & $\tan \delta$ & $A C$ & $M C$ & & & $\tan \delta$ & $A C$ & $M C$ & \\
\hline 1 & $\mathrm{~L}$ & $\mathrm{~L}$ & $\mathrm{~L}$ & 2 & 15 & $\mathrm{~L}$ & $\mathrm{H}$ & $\mathrm{M}$ & 3 \\
\hline 2 & $\mathrm{M}$ & $\mathrm{L}$ & $\mathrm{L}$ & 2 & 16 & $\mathrm{M}$ & $\mathrm{H}$ & $\mathrm{M}$ & 3 \\
\hline 3 & $\mathrm{~L}$ & $\mathrm{M}$ & $\mathrm{L}$ & 2 & 17 & $\mathrm{~L}$ & $\mathrm{~L}$ & $\mathrm{H}$ & 3 \\
\hline 4 & $\mathrm{~L}$ & $\mathrm{~L}$ & $\mathrm{M}$ & 2 & 18 & $\mathrm{M}$ & $\mathrm{L}$ & $\mathrm{H}$ & 3 \\
\hline 5 & $\mathrm{M}$ & $\mathrm{M}$ & $\mathrm{L}$ & 2 & 19 & $\mathrm{~L}$ & $\mathrm{M}$ & $\mathrm{H}$ & 3 \\
\hline 6 & $\mathrm{M}$ & $\mathrm{L}$ & $\mathrm{M}$ & 2 & 20 & $\mathrm{M}$ & $\mathrm{M}$ & $\mathrm{H}$ & 3 \\
\hline 7 & $\mathrm{~L}$ & $\mathrm{M}$ & $\mathrm{M}$ & 2 & 21 & $\mathrm{H}$ & $\mathrm{H}$ & $\mathrm{L}$ & 4 \\
\hline 8 & $\mathrm{M}$ & $\mathrm{M}$ & $\mathrm{M}$ & 2 & 22 & $\mathrm{H}$ & $\mathrm{H}$ & $\mathrm{M}$ & 4 \\
\hline 9 & $\mathrm{H}$ & $\mathrm{L}$ & $\mathrm{L}$ & 3 & 23 & $\mathrm{H}$ & $\mathrm{L}$ & $\mathrm{H}$ & 4 \\
\hline 10 & $\mathrm{H}$ & $\mathrm{M}$ & $\mathrm{L}$ & 3 & 24 & $\mathrm{H}$ & $\mathrm{M}$ & $\mathrm{H}$ & 4 \\
\hline 11 & $\mathrm{H}$ & $\mathrm{L}$ & $M$ & 3 & 25 & $\mathrm{~L}$ & $\mathrm{H}$ & $\mathrm{H}$ & 4 \\
\hline 12 & $\mathrm{H}$ & $\mathrm{M}$ & $M$ & 3 & 26 & $\mathrm{M}$ & $\mathrm{H}$ & $\mathrm{H}$ & 4 \\
\hline 13 & $\mathrm{~L}$ & $\mathrm{H}$ & $\mathrm{L}$ & 3 & 27 & $\mathrm{H}$ & $\mathrm{H}$ & $\mathrm{H}$ & 4 \\
\hline 14 & $\mathrm{M}$ & $\mathrm{H}$ & $\mathrm{L}$ & 3 & & & & & \\
\hline
\end{tabular}

Output membership functions are chosen as 3 equally wide segments since their generation is connected towards the physical aspects of the impact of input variables not the mathematical aspect. Afterwards, the gravity center is calculated from this total output function. The position of this center shows which final output within the range from 2 to 4 is obtained as a result.

\section{Case Study}

The latest results of power transformer oil sample analysis used to test the developed indicator were kindly provided by the Latvian Transmission System Operator.

Results of oil analysis for 9 transformers installed in various substations were chosen to verify proposed method for estimating numerical value of oil analysis indicator. These oil sample parameters are given in Table IV.

Estimation of numerical value of oil analysis indicator for case 1 of the Table IV is shown as an example. First step of the method (see Fig. 4.) is to determine if all 5 oil parameters do not exceed limits of Level 1 of Table II. Values of $\tan \delta$, acidity and moisture content are above these limits. Therefore, it is evaluated if any of the necessary parameters trigger output value $K=5$. Since it is not activated, fuzzy logic block is triggered. 
TABLE IV. VALUES OF INPUT PARAMETER

\begin{tabular}{|c|c|c|c|c|c|}
\hline \multirow{2}{*}{ Case } & \multicolumn{5}{|c|}{ Parameters } \\
\cline { 2 - 6 } & $\begin{array}{c}\text { Flash } \\
\text { point, } \\
{ }^{\boldsymbol{o}} \boldsymbol{C}\end{array}$ & $\begin{array}{c}\text { Flash } \\
\text { point } \\
{ }^{\boldsymbol{o}} \boldsymbol{C}\end{array}$ & $\begin{array}{c}\text { Tan } \boldsymbol{\delta}, \\
\boldsymbol{\%}\end{array}$ & $\begin{array}{c}\text { Acidity, } \\
\mathbf{m g K O H} / \boldsymbol{g}\end{array}$ & $\begin{array}{c}\text { Moisture } \\
\text { content, } \\
\text { ppm }\end{array}$ \\
\hline 1 & 139 & 2 & 2.17 & 0.12 & 10 \\
\hline 2 & 141 & 0 & 0.27 & 0.01 & 7 \\
\hline 3 & 145 & 2 & 0.19 & 0.01 & 4 \\
\hline 4 & 147 & 2 & 1.53 & 0.01 & 5 \\
\hline 5 & 151 & 0 & 0.19 & 0.01 & 14 \\
\hline 6 & 141 & 0 & 3.44 & 0.042 & 6 \\
\hline 7 & 145 & -2 & 1.37 & 0.02 & 7 \\
\hline 8 & 147 & 0 & 3.61 & 0.084 & 17 \\
\hline 9 & 143 & 0 & 12.9 & 0.053 & 7 \\
\hline
\end{tabular}

In this part of the calculation process, algorithm searches through all given rules for a match to the given input data. Rules \#15, \#16, \#22, \#25, \#26 and \#27 from Table III are triggered since the situation of input values matches with the predetermined conditions in these rules. Each of them creates an impact towards one of the possible output values. The final output function is obtained and is displayed in Fig. 6.

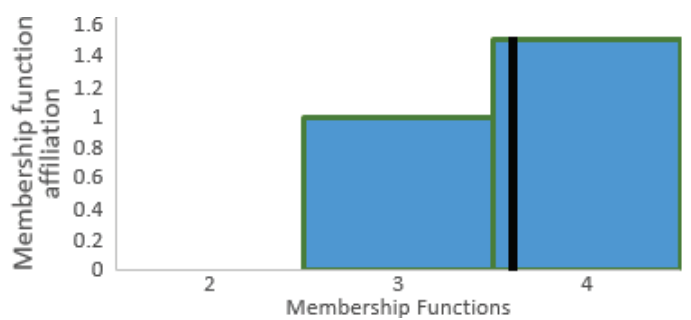

Fig. 6. Generated total output function.

The center of gravity is calculated from this total output function. Its position is within the third segment of the horizontal axis, which corresponds to the score 4 . This result is shown with a black thick vertical line in Fig. 6.

Table $\mathrm{V}$ shows the calculated output values of indicator based on oil analysis for 9 transformers included in this case study. Their values range from 1 to 5 . These obtained values have a strong correlation with the observations made by specialists in practice. Study Case 9 is an example where the oil quality has been evaluated as dangerous and a decision has been taken to change oil for this particular transformer.

TABLE V. CALCUlated NuMERICAL VALUES OF OIL ANALYSIS INDICATOR

\begin{tabular}{|c|l|l|l|l|l|l|l|l|l|}
\hline Case & 1 & 2 & 3 & 4 & 5 & 6 & 7 & 8 & 9 \\
\hline Output Value & $\mathbf{4}$ & $\mathbf{2}$ & $\mathbf{1}$ & $\mathbf{2}$ & $\mathbf{3}$ & $\mathbf{3}$ & $\mathbf{2}$ & $\mathbf{4}$ & $\mathbf{5}$ \\
\hline
\end{tabular}

\section{CONCLUSIONS}

Survey of the literature allows concluding that each power system has to develop its own individual strategy for power transformer risk assessment and development of risk matrix is a common global practice.
To determine numerical values of the indicator based on oil analysis combined approach of binary and fuzzy logic proved to be successful since it allows evaluating risk based on several oil parameters as a single entity. Results from the case study confirms that higher output value corresponds to the transformers that have already attracted-engineers' attention.

Further development of the risk assessment methodology continues with the indicator for power transformer electrical measurements.

\section{ACKNOWLEDGMENT}

This paper has been partly supported by the State Research Program „LATENERGI”.

\section{REFERENCES}

[1] W. Hu, H. Yang, J. Yan, and X. Zhu, "The Transformer Fault Management Information System Design Based on the Risk Assessment," on Proc. High Voltage Engineering and Application (ICHVE), Shanghai, China, Sept. 17-20, 2012, pp. 528 - 531.

[2] T. Suwanasri, C. Suwanasri, and R. Phadungthin, "Risk Assessment Based on Condition and Importance Criteria for Power Transformer in Thailand Transmission Network," John \& Wiley \& Sons, Inc., IEEJ Trans. vol. 10, pp. 18-27, 2015.

[3] K. Taengko, and P. Damrongkulkamjorn, "Risk Assessment for Power Transformers in PEA Substations using Health Index," in Proc. Electrical Engineering/Electronics, Computer, Telecommunications and Information Technology (ECTI-CON), 10th International Conference, Krabi, Thailand, May 15-17, 2013, pp. 1-6.

[4] G. Poiss, "Development of DGA indicator for estimating risk level of power transformers," in Proc. 17th International Scientific Conference on Electric Power Engineering (EPE), Prague, Czech Republic, May 16-18, 2016, pp. 1-4.

[5] Latvian Electrotechnical Commission (LEK) Transformer oil testing. Latvian Energy Standard LEK 118, Latvia, 2014, p. 45. (in Latvian)

[6] T. J. Ross Fuzzy, Logic With Engineering Applications, Third Edition. Singapore: John Wiley \& Sons, 2010.

[7] U. M. Rao, M. V. P. Reddy, and R.K. Jarial, "Fuzzy logic based system to diagnose internal faults of power transformer," in Proc. International Conference on Communication and Industrial Application (ICCIA), Kolkata, West bengal, India, Dec. 26-28, 2011, pp. 1-5.

[8] S. A. Khan, D. Equbal, and T. Islam. "A comprehensive comparative study of DGA based transformer fault diagnosis using fuzzy logic and ANFIS models," IEEE Transactions on Dielectrics and Electrical Insulation, vol. 22, pp. 590-596, 2015.

[9] A. Abu-Siada, M. Arshad, and S. Islam, "Fuzzy logic approach to identify transformer criticality using dissolved gas analysis," on Proc. IEEE PES General Meeting, Detroit, USA, Jul. 25-29, 2010, pp. 1-5.

[10] E. J. Kadim, C. F. Hee, N. Azis, J. Jasni, S. A. Ahmad, and M. Z. A. Ab Kadir, "Dissolved gas analysis of transformers based on rough set and fuzzy logic methods," on Proc. IEEE Conference on Energy Conversion (CENCON), Johor Bahru, Malaysia, Oct. 19-2, 2015, pp. 268-271

Gints Poiss Electrical engineer in Augstsprieguma tikkls JSC and Ph.D. student in Riga Technical University, Department of Electrical Machines and Devices. Focus of the work and study is power transformer diagnostic methods and technical condition assessment. Research interests: power transformer condition's assessment development. 